\title{
Geopolymers Studies in Brazil: A Meta-Analysis and Perspectives
}

\author{
Rodrigo H. Geraldo and Gladis Camarini
}

\begin{abstract}
Geopolymers have stimulated a great interest since it appeared years ago. Many researchers are investigating the structures, characteristics and the formation processes of this promising technology. These materials are a type of binder that in its production sends less carbon dioxide to the atmosphere and requires lower energy consumption when compared to the Ordinary Portland Cement; moreover, it can demonstrate excellent mechanical properties. Brazilian scientific community is also developing researches in this field, and the new policy about the management and disposal of waste, the high growth of the civil construction, among other facts, tends to increase the interest about geopolymers in the country. The aim of this work is to make a meta-analysis of the literature about geopolymers, showing some studies and perspectives about this theme in Brazil.
\end{abstract}

Index Terms-Geopolymers, geopolymerization, perspectives, research.

\section{INTRODUCTION}

Concrete is one of the most traditional building materials and the Ordinary Portland Cement (OPC) is the common binder agent used for its production [1], [2]. The Portland cement-based concrete becomes the highest-volume manufactured product in the world [3].

However, due to a global increase pressure for a healthier environment, OPC production starts to be perceived as unsustainable. The OPC production sends into the atmosphere a considerable amount of carbon dioxide $\left(\mathrm{CO}_{2}\right)$ and it spends much energy that is required for clinker calcination (usually at $1400-1450{ }^{\circ} \mathrm{C}$ ) and grinding of raw materials, coal and clinker [3].

Novel engineering materials arise as more sustainable options. A new type of binder with different designations, but usually known as "geopolymers", appears like an option to reduce greenhouse gas emissions from the concrete production [4], [5], since it has a very small greenhouse footprint when compared to traditional concretes [6]. The technique still utilizes industrial by-products in their formulation and it can offer a possibility of a solution to the immobilization of toxic and radioactive wastes [7]. This explains the growing interest in academic and commercial

\footnotetext{
Manuscript received April 5, 2014; revised July 1, 2014. This work was supported in part by the School of Civil Engineering, Architecture and Urban Design at University of Campinas, UNICAMP, and by the National Counsel of Technological and Scientific Development - CNPq - Brazil.

The authors are with Civil Engineering, Architecture and Urban Design College at University of Campinas, UNICAMP. Campinas, São Paulo, CEP 13083-852, Brazil (e-mail: henriquegeraldo@uol.com.br, gcamarini@gmail.com,camarini@fec.unicamp.br).
}

areas recently, where the potential for $\mathrm{CO}_{2}$ emission reductions can be appointed as the key factor [8].

The Geopolymer research was conducted through a meta-analysis of data obtained in Brazilian literature, evaluating the research works on the subject published in nine years (2005-2014), both in academic papers and in magazines, and in major conferences on engineering and materials science.

\section{GEOPOLYMERS}

Alkali-activated binders or "geopolymers" are the product of a reaction between an alkali source (usually a liquid) with a solid aluminosilicate precursor at or above room temperature [3]-[9].

These materials are inorganic polymers but they are synthesized in a manner similar to thermosetting organic polymers. It is presumed that the geopolymers are formed by dissolution of alumina and silica into a silicate solution occurring the polycondensation of these monomers into aluminosilicate anions [10].

Davidovits [11], [12] was the first author to apply the term "geopolymer" (that is nowadays normally used designation for this technology), being the pioneered in the use of calcium-free systems based on calcined clays [13].

Chemically, the designation given for geopolymer based on aluminosilicate was poly (sialate), being sialate an abbreviation for silico-oxo-aluminate. The sialate network consists of $\mathrm{SiO}_{4}$ and $\mathrm{AlO}_{4}$ tetrahedra linked alternately by sharing all oxygen atoms. Positive ions $\left(\mathrm{Na}^{+}, \mathrm{K}^{+}, \mathrm{Li}^{+}, \mathrm{Ca}^{2+}\right.$, $\mathrm{Ba}^{2+}, \mathrm{NH}_{4}, \mathrm{H}_{3} \mathrm{O}^{+}$) must be present in the framework cavities to balance the negative charge of $\mathrm{Al}^{3+}$ in tetrahedral coordination [12]. Fig. 1 shows the three types of polysialate distinguished.

Geopolymers compounds can be either crystalline or amorphous. Crystalline poly (sialate) and poly(sialate-siloxo) result of hydrothermal setting conditions, while the hardening at ambient temperature induces amorphous structure [11].

Geopolymeric materials can polyconsense at low temperatures and acquire properties and structures similar to ceramic materials [11], such as resistance against acids and high temperatures [14]. Among the different properties that they can exhibit are formability, high compressive strength and chemical resistance [10].

The final material shows similarities in the molecular structure and nanostructure, but there are differences in the properties of geopolymers that depends directly on the nature of the initial raw materials [15].

Researchers identified many kinds of raw materials that the use as aluminosilicate precursor is possible, prioritizing 
materials of low cost and readily available. In this sense, many kinds of industrial waste and natural materials were considered able [16]. Some examples of aluminosilicate precursors in current literature are fly ash, blast furnace slag, albite, feldspar, tungsten mine waste, kaolin, metakaolin, metallurgical slags, rice husk ash, among others [13]-[18] Those fly ash-based ones are usually more durable and strong [15].

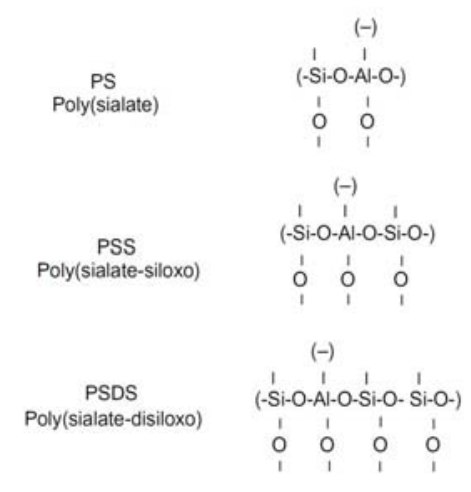

Fig. 1. Types of polysialates [11].

Some factors such as the $\mathrm{CaO}$ and $\mathrm{K}_{2} \mathrm{O}$ content, and the molar $\mathrm{Si}-\mathrm{Al}$ in the original mineral, the type of alkali, the extent of dissolution of $\mathrm{Si}$ and the molar $\mathrm{Si} / \mathrm{Al}$ ratio in solution have a correlation with the final compressive strength [17].

The presence of calcium compounds tends to improve the compressive strength of geopolymers. There are two reasons proposed for the increase in mechanical behavior of geopolymers by addition of calcium compounds to raw materials: the precipitation of calcium silicate hydrate or calcium silicate aluminate phases and catalysis of the dissolution of Al-Si particles in alkali solution [16].

Geopolymers materials still have some barriers to overcome, especially that derived from the traditional position of OPC in the world. Another issue is that the construction industry is quite conservative in adopting new technologies and products that will replace existing ones [19] However, the geopolymers are not necessarily a product competing with OPC, but rather a technology which will offer a broader range of binder products to the building market [18].

\section{GEOPOLYMERIZATION}

Geopolymerization can be considered the result of the polycondensation of still hypothetical monomers, the orthosialate ions. It is an exothermic reaction [11]. It consists of dissolution and hydrolysis followed by a condensation step in an alkaline silicate plus alumino-silicate system [16].

It has believed that the chemistry involved in geopolymerization is similar with the synthesis of zeolites, although the resultant products are different in composition and structure [20]. Fig. 2 illustrates the schemes of reactions proposed for the polycondensation process.

In the reactions (1) and (2) the amount of Al-Si materials used depend on the particle size, the extent of dissolution of $\mathrm{Al}-\mathrm{Si}$ materials and the concentration of the alkaline solution.

The formation of $\left[\mathrm{Mz}\left(\mathrm{AlO}_{2}\right)_{x}\left(\mathrm{SiO}_{2}\right)_{y} \cdot \mathrm{MOH} \cdot \mathrm{H}_{2} \mathrm{O}\right]$ gel is a dominant step in the geopolymerization and essentially relies on the extent of dissolution of aluminosilicate materials (reaction 3). The dissolution from the surfaces of the aluminosilicate materials formed the gel phase [17]-[19].

$$
\begin{aligned}
& \text { Al-Si material (s) }+\mathrm{MOH}(\mathrm{aq})+\mathrm{Na}_{2} \mathrm{SiO}_{3}(\mathrm{~s} \text { or aq) } \\
& \mathrm{Al}-\mathrm{Si} \text { material }(\mathrm{s})+\left[\mathrm{M}_{z}\left(\mathrm{AlO}_{2}\right)_{x}\left(\mathrm{SiO}_{2}\right)_{y} \cdot n \mathrm{MOH} \cdot m \mathrm{H}_{2} \mathrm{O}\right] \mathrm{gel}
\end{aligned}
$$

Fig. 2. Reaction scheme proposed for geopolymerization [17].

The alkali silicate acts as a binder and keeps the particulates together to form a hardened dispersion or chemically bonded ceramic. The increase of curing temperature may reduce the extent of the amorphous order within the glue [21].

Fig. 3 shows the basic concept model of geopolymerization. This conceptual/mathematical model developed for metakaolin or fly ash as source of alluminosilicate, indicates the steps occurred in this complex process [8].

The silica content is fundamental in dictating the molecular mechanisms occurring during geopolymerization [22].

Adding silicate is one of the essential reactants in geopolymerization, which makes $\mathrm{Si}$ complexes more favorable to polymerization with aluminate once leaches from Al-Si surface [20].

It is necessary to enhance the activity and solubility of Al-Si source materials in alkali solution to achieve a well-structured geopolymer with acceptable mechanical properties. A way to meet this condition is the thermal activation of the source material, being this thermal activation process and its effects on final properties subject of several studies [16].

The comprehension of the geopolymerization process is very important, since it can provide the key to control many facts such as the degree of polymerization and the porosity along mechanical properties of geopolymers [23].

\section{GeOpolymers StUdies In BRAZIL}

This topic presents, briefly, some investigations, methods, results and conclusions of researches available in Brazilian literature about geopolymer in the period 2005-2014.

Livi [24] examined the influence of some factors such as activator solution-to-fly ash ratio, concentration of solution-based sodium hydroxide, and curing temperature in the production of fly ash-based geopolymers. The experimental program was established in ratio $\mathrm{Si} / \mathrm{Al}=2.8 \%$; molar concentration $=8,12$ and $16 \mathrm{M}$; activator solution-to-fly ash ratio $=0.50,0.55$ and $0.60 \mathrm{~g} / \mathrm{g}$; curing temperature $=45^{\circ} \mathrm{C}, 65^{\circ} \mathrm{C}$ and $85^{\circ} \mathrm{C}$; duration $=22$ hours. The results showed that curing at $65^{\circ} \mathrm{C}$ and $85^{\circ} \mathrm{C}$ had good resistance at only one day of age. The final mechanical 
properties could be improved by decreasing activator solution-to-fly ash ratio or increasing molarity, although changing the molarity was more advantageous. The mixture made with a $16 \mathrm{M}$ sodium hydroxide solution, activator solution-to-fly ash ratio 0.55 and curing temperature of $85^{\circ} \mathrm{C}$ offered the highest compressive strength, according to the conditions of the experiment. Fig. 4 illustrates the results of compressive strength of the samples after 28 days. Some analysis also revealed that to a geopolymeric paste with a resistance of $24 \mathrm{Mpa}$, the estimated carbon dioxide equivalent emission was $0,04 \mathrm{tCO}_{2}$, while for a Portland cement paste with the same mechanical performance, this number was around $0,41 \mathrm{tCO}_{2}$.

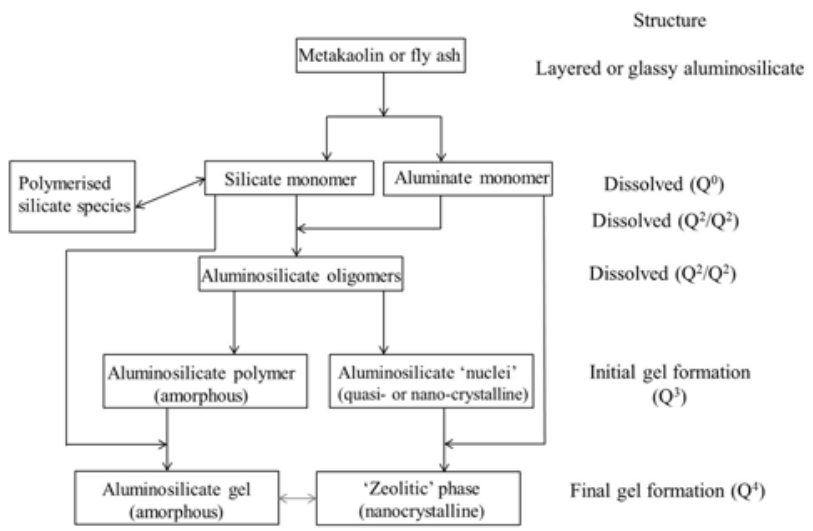

Fig. 3. Schematic diagram of a conceptual/mathematical model for alkaline activation of a low- $\mathrm{Ca}$ aluminosilicate source such as metakaolin or low-Ca fly ash [8].

The possibility of reusing the fly ashes generated for a Brazilian electricity company in obtaining geopolymers was tested by Blissari et al. [25]. The fly ashes were the unique aluminosilicate sources for the research. The hydroxide type (sodium and potassium), its concentration (10 and 20M) and the temperature $\left(50{ }^{\circ} \mathrm{C}\right.$ and $80{ }^{\circ} \mathrm{C}$ ) were the experimental factors. They concluded that the type of the alkali solution does not change the compressive strength of the system, but the molarity of the solution and the temperature of the synthesis have a great influence in modifying this property.

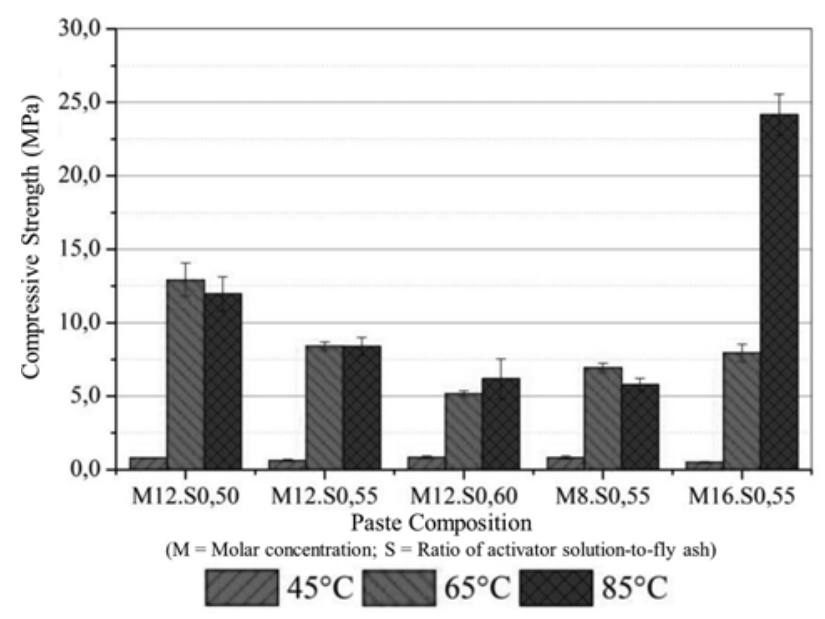

Fig. 4. Compressive strength of the samples after 28 days [24].

The higher the molarity utilized, the lower is the resistance obtained; and the higher the temperature synthesis, the lower is the compressive strength. The results presented the feasibility of the proposed use. It was observed that the fly ashes fineness is an important issue and a necessary pre-treatment.

A survey evaluated the influence of the ceramic waste addition in geopolymers pastes was developed by Pinto [26]. Some tests as specific gravity and compressive strength were driven and they revealed that the pastes have high mechanical strength to a light paste, low filtrate volume and low permeability. It was found that geopolymer resultant is an amorphous material, with a peak of crystalline kaolinite. The optimum range of waste ceramic use in geopolymer paste was between $2.5 \%$ and $5 \%$.

Melo [27] developed a research where the main goal was to have a better comprehension of how the geopolymer structure arises from the mineral phases of phyllite, from a mineralogical point of view. It was used sodium silicate and, as an aluminosilicate precursor for the geopolymeric material production, a calcined phyllite as a partial or a total substitute of metakaolin. The total amount of available material for reactivity in the calcined phyllite is less than $40 \%$. Tests of compressive strength of the produced geopolymers indicated that the maximum value was with the substitution of $40 \%$ metakaolin by phyllite. The phyllite-based geopolymer was not fully hardened after the curing time and it showed low mechanical strength.

Bitencourt et al. [28] used the bauxite waste to geopolymers production. The molar ratio of $\mathrm{SiO}_{2} / \mathrm{Al}_{2} \mathrm{O}_{3}=3.8$ and $\mathrm{Al}_{2} \mathrm{O}_{3} / \mathrm{M}_{2} \mathrm{O}=1.0$ was constant for all the samples. The percentages of the components in the mixture - bauxite waste, water, metakaolin, silicate, $\mathrm{KOH}$ and eventually $\mathrm{Ca}(\mathrm{OH})_{2}-$ were different to verify the better condition to geopolymer production. It was observed that there is an improvement in the properties of the final product with calcium hydroxide in the composition with less quantity of metakaolin and higher content of the bauxite waste. All the samples were submitted to a thermal treatment at a temperature of $800{ }^{\circ} \mathrm{C}$. This resulted in higher compressive strength (until $24 \mathrm{MPa}$ ). To qualify the leaching resistance of the final material it was conducted tests of the $\mathrm{pH}$ from leachate and electric conductivity, that showed that the burning of geopolymers with bauxite waste in temperatures lower than $600^{\circ} \mathrm{C}$ is not enough to passivate the structures of the material and thus avoid the leaching ions. The results reveal a potential for the bauxite waste utilization in geopolymers production.

Mauri et al. [29] studied the durability of a geopolymer mortar in highly aggressive environments, compounds by sodium sulfate and sulfuric acid, in solutions with $10 \mathrm{wt} \%$ and $5 \mathrm{wt} \%$ concentration, respectively. The geopolymer mortar was produced with metakaolin, Portland cement (source of $\mathrm{CaO}$ ), potassium hydroxide and alkaline sodium silicate. The compressive strength was analyzed in composites submitted to aggressive ions in different cycles: 2, 4, 6 and 8. The geopolymer in sodium sulfate solution had a decrease of $17 \%$ of the compressive strength at the end of the fourth cycle, and the geopolymer maintained in sulfuric acid solution had a decrease of $72 \%$ compared to the reference. Fig. 5 shows the compressive strength values.

The results indicated that the geopolymer mortar kept in the sodium sulfate solution showed a small drop in the compressive strength when compared to the reference mortar, 
while it was observed a considerable decrease of this property with a sulfuric acid solution.

Pereira et al. [30] observed the microstructure of a geopolymer concrete, comparing the results with the microstructural analysis of the Portland cement-based concrete available in the literature. Geopolymer concrete was prepared with potassium hydroxide, metakaolin, sodium silicate (extra source of $\mathrm{Si}$ ), blast furnace slag and quartz river sand (aggregate). Some tests, such as thermal and X-ray diffraction, were conducted. The results indicated that the atomic structure of the geopolymer concrete showed low crystallinity, high compressive strength and a dense and of $\mathrm{Ca}(\mathrm{OH})_{2}$ free microstructure. The Portland cement-based concrete microstructure is composed for a high diversity of phases, while the geopolymer concrete is composed, basically, of sodium, potassium and calcium aluminosilicate.

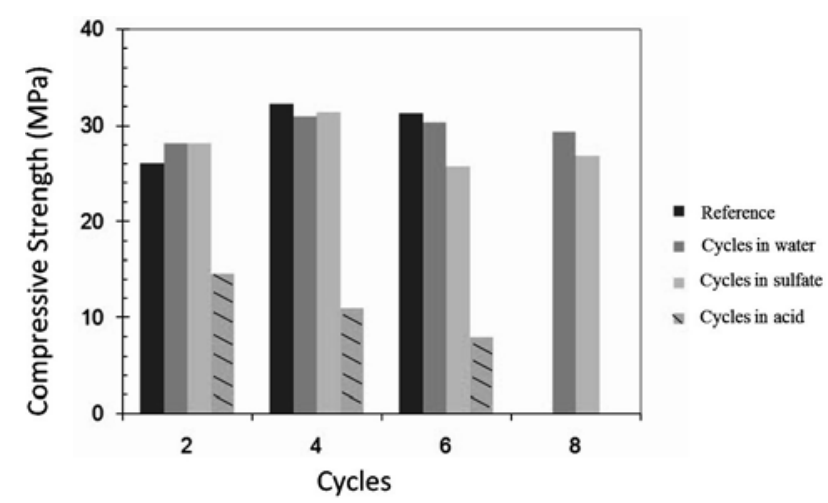

Fig. 5. Compressive strength of geopolymer mortar subjected to different conditions of exposition [29].

Severo et al. [31] evaluated the feasibility of using mineral waste in geopolymer production, as an alternative to minimize the environmental impacts caused for these residues. $\mathrm{NaOH}$ was used as an alkaline activator in the molar ration of $2 \mathrm{Si}: 1 \mathrm{Al}: 1 \mathrm{Na}$, and the waste from kaolin industry and sawing granite were utilized. They concluded, by compressive strength tests, that the higher amount of thin and calcined kaolin waste favors the mechanical properties of the final material, with the development of denser microstructures and with lower pore size.

Barroso [32] intended to obtain a geopolymer adding particles of a quasicrystalline alloy system Al-Cu-Fe for the formulation of composite. The influence of adding different amounts of water in the resistance of the composites was also analyzed. Geopolymer matrix composites with volume fractions of quasicrystalline alloy particles equal to $5 \%, 10 \%$ and $17 \%$ were prepared. The matrix composites were characterized structurally and mechanically and the scanning electron microscopy results showed a good adhesion between the matrix and dispersed phase. For contents higher than 5\% of quasicrystals in the geopolymer matrix, there was an effect in reduction of the composites resistance. The increase of quasicrystals also interfered the rupture type, where higher contents implicated in weaker composites. The water addition delayed the gain of initial resistance of the samples and it interfered directly in the material performance. The results of mechanical tests allowed concluding that the composite best performance was with $5 \%$ by volume of quasicrystalline phase, without water addition.
The biodiesel plants generate a considerable amount of byproducts during the production process. Some of these have a high $\mathrm{pH}$, as is the case of the water purification of biodiesel. Since the geopolymers productions demand an alkaline activator, Sousa [33] analyzed the feasibility of using the potassium hydroxide obtained of wash water from the biodiesel production process to make geopolymers, aiming the production of pressed structural blocks. It was also used sodium silicate and sodium hydroxide (alkaline activators), soil, water and metakaolin to produce the geopolymers. There were prepared samples just with geopolymers, geopolymers plus liquid waste from biodiesel and only Portland cement to observe the difference between their behaviors. Mechanical strength, durability, microstructure and physical properties of the different samples produced were examined. The results showed that some sources of liquid waste from biodiesel remains alkaline even after many washes sequences (soil and cottonseed oil), while others lost their alkalinity after two wash cycles (sunflower). The microstructure of the matrix alkali-activated has a more homogeneous interface with the silicon aggregates, being constituted by aluminium, sodium, silicon, and traits of iron, potassium, chlorine and sulfur. Samples with geopolymers showed better results for the durability tests when compared to the Portland cement samples. The mechanical properties with biodiesel waste were similar to those made with Portland cement only, and the mechanical strength depends on the concentration of metakaolin used in the mixture. The results indicated that it is possible to use the liquid waste from biodiesel of several sources in geopolymers production, since it presented an appropriate alkalinity.

Boca Santa [34] searched information about the viability of producing geopolymers using bottom ash from coal burning and calcined paper sludge as aluminosilicate precursors. It was utilized sodium hydroxide (5, 10 and $15 \mathrm{M}$ ) and sodium silicate $\left(\mathrm{SiO}_{2} / \mathrm{Na}_{2} \mathrm{O}=1.58\right)$ as alkali-activator. Being the paper residues rich in $\mathrm{CaCO}_{3}$, this material passed for a pretreatment by purification with hydrochloric acid, in order to remove the $\mathrm{CaCO}_{3}$ content. Chemical analyses revealed that the bottom ash $\mathrm{SiO}_{2} / \mathrm{Al}_{2} \mathrm{O}_{3}$ ratio is $2: 1$, being suitable for geopolymeric reaction. The samples were characterized by X-ray diffraction, Fourier transformed infrared spectroscopy and scanning electron microscopy. Compressive strength of samples molded only with geopolymer paste (without aggregates) was measured in 4 different intervals (1, 7, 28 and 90 days). The results allow concluding that the use of coal bottom ash and calcined paper to produce geopolymers is viable. Compressive strength was between 10-25 $\mathrm{MPa}$, where the higher setting time generates a greater strength. In samples prepared with an alkaline mixture of $15 \mathrm{Mol} / 1$ the reaction was faster and the results better. In a 2:1 ratio (bottom ash and calcined paper sludge) it was reached the best result.

Barros et al. [35] investigated the adhesion properties of a geopolymer-based adhesive on metallic substrates in several surface conditions. It was used metakaolin as aluminosilicate source and sodium silicate with the 2.17 ratio $\left(\mathrm{SiO}_{2} / \mathrm{Na}_{2} \mathrm{O}\right)$ was the alkali-activator. Molar ratio was established in $\mathrm{SiO}_{2} / \mathrm{Al}_{2} \mathrm{O}_{3}=4.7, \mathrm{M}_{2} \mathrm{O} / \mathrm{SiO}_{2}=0.3$ and $\mathrm{H}_{2} \mathrm{O} / \mathrm{M}_{2} \mathrm{O}=10$. The 
adhesive was cured at $55^{\circ} \mathrm{C}$ during 24 hours. The surface of steel and aluminum received mechanical (grit-blasting or sand-blasting) and, eventually, chemical (silanization or nitric-phosphoric acid) treatments, being prepared six samples in distinct conditions. Some tests showed that chemical treatments were not effective on bond strength for both steel and aluminum joints, and a higher strength geopolymer was achieved with steel when compared to the aluminum joints.

Souza [36] studied the development of alkali-activated adhesives, verifying their shear resistance in aluminum bonded joints. To produce the geopolymer adhesive it was used metakaolinite and soils calcined as precursors, and potassium and sodium silicate as alkali-activators. It was investigated 22 distinct formulations (11 for each precursor), changing the ratio between the potassium silicate and the sodium silicate. Curing occurred at $55^{\circ} \mathrm{C}$ temperature during 24 hours for all the samples. The results of the pure shear test showed that the adhesive made from metakaolinite with $20 \%$ of potassium silicate had the best performance, achieving $70 \%$ of the shear resistance obtained with commercial epoxy. Among the adhesives made from soil calcined, the best result happened to $30 \%$ of potassium silicate that reached $80 \%$ of the shear resistance obtained with commercial epoxy. For the metakaolinite-based adhesives it was observed that the alkali-activators mixture is not essential, while calcined soil-based adhesives had an increase in the mechanical resistance with the activators mixture. It is supposed that a curing time longer than 24 hours can still provide better results.

Pelisser et al. [37] aimed to characterize the mechanical and micro-nanomechanical properties of metakaolin-based geopolymers. Sodium silicate and sodium hydroxide were used in different proportions as alkali-activators, being the molar ratio of $\mathrm{Na}_{2} \mathrm{OSiO}_{2} / \mathrm{NaOH}$ established in $2.2,1.6$ and 1.0. It was adopted the curing temperature of $40^{\circ} \mathrm{C}$ and the $\mathrm{H}_{2} \mathrm{O}$ /Metakaolin ratio of 0.75 . Elastic modulus, hardness, compressive and flexural strength and flexural modulus were determined. The intermediate molar ratio of $\mathrm{Na}_{2} \mathrm{OSiO}_{2} / \mathrm{NaOH}$ used provided the best results of elastic modulus and hardness. A higher molar ratio was similar in results, while the lower molar ratio implicated in a decrease of the mechanical properties. The products presented high flexural strength and a great relationship between the flexural and compressive strength. This geopolymer produced was also used to make mortars, where the higher performance occurred when mixed with sand (1:3 in mass). Geopolymer micro-nanomechanical results revealed a hardness, a greater deformation capacity and tensile strength very similar to the Portland cement.

Through a gel-casting process, Cilla et al. [38] evaluated the production of highly porous open cell components from geopolymer precursors, using the geopolymerization reaction to stabilize the gas bubbles introduced in the liquid slurry by rotational mixing. It was prepared a geopolymer using metakaolin, fly ash class $\mathrm{F}$, potassium hydroxide and potassium silicate (a mixture of potassium hydroxide and potassium silicate with $(\mathrm{Si} / \mathrm{K}=1.66)$. The oxide molar ratios were defined as $\mathrm{SiO}_{2} / \mathrm{Al}_{2} \mathrm{O}_{3}=3.78, \mathrm{~K}_{2} \mathrm{O} / \mathrm{SiO}_{2}=0.24$ and
$\mathrm{H}_{2} \mathrm{O} / \mathrm{K}_{2} \mathrm{O}=16$. The foams received a pretreatment, remained at $80^{\circ} \mathrm{C}$ during 20 minutes, when then it received a surfactant addition of $2 \mathrm{wt} \%$ to $4 \mathrm{wt} \%$. Some investigations allowed concluding that processing parameters and the type of non-ionic surfactant affect the characteristics and morphology of the foams. Results suggested that the material could be used as a low cost replacement in several applications.

TABLE I: SUMMARY OF BRAZILIAN RESEARCH ABOUT GEOPOLYMERS (2005-2014)

\begin{tabular}{|c|c|c|}
\hline Author(s) & Year & Main Proposal \\
\hline $\begin{array}{l}\text { Pereira et al. } \\
{[30]}\end{array}$ & 2005 & $\begin{array}{c}\text { Compare the microstructure of a geopolymer } \\
\text { concrete with the microstructure of a Portland } \\
\text { cement-based concrete }\end{array}$ \\
\hline $\begin{array}{l}\text { Mauri et al. } \\
\text { [29] }\end{array}$ & 2009 & $\begin{array}{l}\text { Analyze the durability of a geopolymer } \\
\text { mortar in aggressive environments }\end{array}$ \\
\hline Barroso [32] & 2009 & $\begin{array}{l}\text { Obtain a geopolymer adding particles of a } \\
\text { quasicrystalline alloy system } \mathrm{Al}-\mathrm{Cu}-\mathrm{Fe} \text { for } \\
\text { the formulation of composite }\end{array}$ \\
\hline Souza [36] & 2009 & $\begin{array}{l}\text { Develop alkali-activated adhesives and verify } \\
\text { their shear resistance in aluminum bonded } \\
\text { joints. }\end{array}$ \\
\hline $\begin{array}{l}\text { Blissari et al. } \\
{[25]}\end{array}$ & 2011 & $\begin{array}{l}\text { Reuse fly ashes generates for an electricity } \\
\text { company to obtain geopolymers }\end{array}$ \\
\hline Pinto [26] & 2011 & $\begin{array}{l}\text { Evaluate the influence of the ceramic waste } \\
\text { addition in geopolymers pastes }\end{array}$ \\
\hline Melo [27] & 2011 & $\begin{array}{l}\text { Understand better how the geopolymer } \\
\text { structure arises from the mineral phases of } \\
\text { phyllite, from a mineralogical point of view }\end{array}$ \\
\hline Sousa [33] & 2011 & $\begin{array}{c}\text { Use the potassium hydroxide obtained of } \\
\text { wash water from the biodiesel production } \\
\text { process to make geopolymers }\end{array}$ \\
\hline $\begin{array}{l}\text { Bitencourt et } \\
\text { al. }[28]\end{array}$ & 2012 & $\begin{array}{l}\text { Identify a correct destination for bauxite } \\
\text { residue through geopolymer applications }\end{array}$ \\
\hline $\begin{array}{l}\text { Barros et al. } \\
{[35]}\end{array}$ & 2012 & $\begin{array}{l}\text { Investigate adhesion properties of a } \\
\text { geopolymer-based adhesive on metallic } \\
\text { substrates in several surface conditions }\end{array}$ \\
\hline $\begin{array}{l}\text { Altidis et al. } \\
\text { [39] }\end{array}$ & 2012 & $\begin{array}{c}\text { Evaluate the influence of incorporating } \\
\text { quasicrystal powders in geopolymer } \\
\text { composites on the adherence of metallic } \\
\text { substrates }\end{array}$ \\
\hline $\begin{array}{l}\text { Silva et al. } \\
\text { [40] }\end{array}$ & 2012 & $\begin{array}{c}\text { Produce geopolymer matrix composites } \\
\text { adding quasicrystals }\end{array}$ \\
\hline Livi [24] & 2013 & $\begin{array}{l}\text { Analyze the influence of several factors in the } \\
\text { production of fly ash-based geopolymers }\end{array}$ \\
\hline $\begin{array}{l}\text { Severo et al. } \\
{[31]}\end{array}$ & 2013 & $\begin{array}{l}\text { Evaluate the feasibility of using mineral } \\
\text { waste in geopolymer production }\end{array}$ \\
\hline $\begin{array}{l}\text { Boca Santa et } \\
\text { al. [34] }\end{array}$ & 2013 & $\begin{array}{l}\text { Synthesize geopolymers from bottom coal } \\
\text { ash and calcined paper sludge as } \\
\text { aluminosilicate precursors }\end{array}$ \\
\hline $\begin{array}{l}\text { Pelisser et al. } \\
\text { [37] }\end{array}$ & 2013 & $\begin{array}{l}\text { Characterize the mechanical and } \\
\text { micro-nanomechanical properties of a } \\
\text { metakaolin-based geopolymer cement }\end{array}$ \\
\hline $\begin{array}{l}\text { Cilla et al. } \\
{[38]}\end{array}$ & 2014 & Produce Geopolymer foams by gelcasting \\
\hline
\end{tabular}

A composite made of geopolymer matrix reinforced with quasicrystal powders was developed for Altidis et al. [39] to evaluate the influence of this incorporation on the adherence of metallic substrates. The geopolymer was prepared with metakaolin and sodium silicate and the different proportions of quasicrystal/geopolymer volume fraction tested were $5 \%$, $10 \%$ and $15 \%$. Single-Lap Joints tests were conducted to measure the joint strength, considering two distinct curing times ( 7 and 28 days). The results showed that there were increases in the bond strength as the quasicrystal/geopolymer volume increased, thus the composites with $15 \%$ of 
quasicrystal achieved highest values for bond strength (5.9 $\mathrm{MPa}$ after 28 days of curing). It suggests that the addition of quasicrystal provided an increase in adhesive properties, generating an improvement in adherence.

Silva et al. [40] produced geopolymer matrix composites adding quasicrystals, being tested three different ratios $(10 \%$, $20 \%$ and $30 \%$ of quasicrystal in volume). It was produced a metakaolin-based geopolymer with sodium silicate. Some tests showed that without the thermal treatment, the samples presented a homogeneous distribution of quasicrystalline reinforcement in the geopolymer matrix. The higher contents of quasicrystals revealed a decrease of cracks in relation to the pure geopolymer. The thermal treatment $\left(400{ }^{\circ} \mathrm{C}\right.$ for one hour) of the composites did not generate an increase in the material porosity, what occurred in pure geopolymer. It is suggested that it can be a consequence of the catalyst effect of quasicrystals.

Table I shows a summary of the Brazilian researches presented in this paper, indicating the authors, year, and principal goal. The results achieved were always positive, according to the proposed of the studies, giving perspectives of new studies on this subject.

\section{Perspectives for the Future}

In Brazil, several recent facts may motivate new geopolymers researches, increasing more and more the science community interest about this technology, such as.

\section{A. The Civil Construction is Increasing and Still Lack Many Houses in the Country}

Studies indicate that between the years of 2004 and 2011 the civil construction in Brazil registered the growth average annual rate of 5\% [41]. Accumulated, the sector grew up $63 \%$ from 2007 until 2011. It drives directly the search for building materials [42]. Cements, for example, had an expansion in sales of $10.1 \%$ in 2008 about 2007 [43]. Moreover, considering that in 2011 the Brazilian housing deficit was about 5.4 million of domiciles [44], it is suggested that the civil construction sector will still continue to expand during the next years. It is a very favorable scenario to keep on developing studies about geopolymers, which may appear as an alternative product in this growing market.

\section{B. Recent Brazilian Regulation Limits the Waste Dumping in Landfills, Prioritizing Others Alternatives}

Since 2010, the National Solid Waste Policy [45] has considered the waste generators responsible for it. The law indicates that in the management of waste, the sequence of priority to observe is not generation, reduction, reutilization, recycle, treatment of the residues and environmental correctly final destination of the refuse. It requires that only wastes without available technologies of reuse or recycle can have the disposal in landfills. In this sense, the feasibility of several types of wastes - industrials, minerals, from thermal electricity production, agricultural - in geopolymers production offers a viable alternative - economic and environmental - for the managers in complying with the reported law. Investigations about aluminosilicate precursors for geopolymers produce, may evidence the possibility of new kinds of waste appropriate to this correct utilization, where the waste turns to a by-product of interest.

\section{Brazil Determined to Decrease the Amount of Greenhouse Gases that Sends to the Atmosphere}

The worldwide concern about the climate changes has pressed authorities in establishing greenhouse gas reduction targets. In Brazil, an important step occurred through the entitled National Policy about Climate Changes [46]. In this law, it was assumed the compromise to reduce the country emissions of greenhouse gases between $36.1 \%$ and $38.9 \%$ designed until 2020. As argued in the introduction, the fact of geopolymer production to send less carbon dioxide (considered a greenhouse gas) than OPC to the atmosphere, makes the development of this material a relevant alternative in reaching reductions of greenhouse gas emissions.

\section{CONCLUSION}

This paper shows that different lines of research about geopolymers theme were conducted in Brazil recently; however, the database used allows observing that it is still concentrated in some few universities around the country.

Different geopolymers raw materials were examined for Brazilian researchers, such as bauxite waste, fly ashes, ceramic and mineral wastes, wash water from biodiesel production, among others. It was also analyzed the use of reinforcing agents, durability, structures and properties of several types of these products.

Some facts, presented in this work, and the own advantages of geopolymers may stimulate further the interested about this technology, promoting a wider field of studies in this area.

\section{REFERENCES}

[1] L. K. Turner and F. G. Collins, "Carbon dioxide equivalent $\left(\mathrm{CO}_{2}-\mathrm{e}\right)$ emissions: A comparison between geopolymer and OPC cement concrete," Construction and Building Materials, vol. 43, pp. 125-130, Jan. 2013.

[2] G. Habert, J. B. E. D. Lacaillerie, and N. Roussel, "An environmental evaluation of geopolymer based concrete production: reviewing current research trends," Journal of Cleaner Production, vol. 19, pp. 1229-1238, March 2011.

[3] Z. Zhang, J. L. Provis, A. Reid, and H. Wang, "Geopolymer foam concrete: an emerging material for sustainable construction," Construction and Building Materials, vol. 56, pp. 113-127, Jan. 2014.

[4] B. C. M. Lellan, R. P. Williams, J. Lay, A. V. Riessen, and G. D. Corder, "Costs and carbon emissions for geopolymer pastes in comparison to ordinary portland cement," Journal of Cleaner Production, vol. 19, pp. 1080-1090, Febr. 2011.

[5] T. Bakharev, J. G. Sanjayan, and Y. B. Cheng, "Effect of admixtures on properties of alkali-activated slag concrete," Cement and Concrete Research, vol. 30, pp. 1367-1374, June 2000.

[6] P. Duxson, J. L. Provis, G. C. Lukey, and J. S. J. V. Deventer, "The role of inorganic polymer technology in the development of "green concrete," Cement and Concrete Research, vol. 37, pp. 1590-1597, Aug. 2007.

[7] H. Xu and J. S. J. V. Deventer, "Geopolymerisation of multiple minerals," Minerals Engineering, vol. 15, pp. 1131-1139, Oct. 2002

[8] J. L. Provis, "Geopolymers and other alkali activated materials: why, how, and what?" Materials and Structures, vol. 47, pp. 11-25, Nov. 2013.

[9] S. A. Bernal and J. L. Provis, "Durability of alkali-activated materials: progress and perspectives," Journal of the American Ceramic Society, vol. 97, pp. 1-12, Jan. 2014. 
[10] J. P. Hos, P. G. M. Cormick, and L. T. Byrne, "Investigation of a synthetic aluminosilicate inorganic polymer," Journal of Materials Science, vol. 37, pp. 2311-2316, 2002.

[11] J. Davidovits "Geopolymers: inorganic polymeric new materials," Journal of Thermal Analysis, vol. 37, pp. 1633-1656, 1991.

[12] J. Davidovits, "Geopolymers and geopolymeric materials," Journal of Thermal Analysis, vol. 35, pp. 429-441, 1989.

[13] P. Duxson, et al, "Understanding the relationship between geopolymer composition, microstructure and mechanical properties," Colloids and Surfaces A: Physicochem. Eng. Aspects, vol. 269, pp. 47-58, June 2005.

[14] P. Sukmak, S. Horpibulsuk, S. Shen, P. Chindaprasirt, and C. Suksiripattanapong, "Factors influencing strength development in clay-fly ash geopolymer," Construction and Building Materials, vol. 47, pp. 1125-1136, June 2013

[15] P. Duxson et al., "Geopolymer technology: the current state of the art," Journal of Materials Science, vol. 42, pp. 2917-2933, Dec. 2006.

[16] B. Majidi, "Geopolymer technology, from fundamentals to advanced applications: a review," Materials Technology, vol. 24, pp. 79-87, May 2009.

[17] H. Xu and J. S. J. V. Deventer, "The geopolymerisation of alumino-silicate minerals," International Journal of Mineral Processing, vol. 59, pp. 247-266, Jan. 2000.

[18] P. Duxson and J. L. Provis, "Designing precursors for geopolymer cements," Journal of the American Ceramic Society, vol. 91, pp. 3864-3869, Sept. 2008.

[19] K. Komnitsas and D. Zaharaki, "Geopolymerisation: a review and prospects for the minerals industry," Minerals Engineering, vol. 20, pp. 1261-1277, Sept. 2007.

[20] H. Xu, "Geopolymerisation of aluminosilicate minerals," Ph.D. Dissertation, Dept. of Chemical Engineering, University of Melbourne, Australia, 2002.

[21] J. W. Phair, J. D. Smith, and J. S. J. V. Deventer, "Characteristics of aluminosilicate hydrogels related to commercial geopolymers," Materials Letters, vol. 57, pp. 4356-4367, March 2003.

[22] C. E. White, J. L. Provis, T. Proffen, and J. S. J. V. Deventer, "Molecular mechanisms responsible for the structural changes occurring during geopolymerization: multiscale simulation," AIChE Journal, vol. 58, pp. 2241-2253, July 2012.

[23] M. S. M. Villarreal et al., "The effect of temperature on the geopolymerization process of a metakaolin-based geopolymer," Materials Letters, vol. 65, pp. 995-998, Jan. 2011.

[24] C. N. Livi, "Desenvolvimento de pasta de geopolímeros a base de cinza volante e hidróxido de sódio," MSc. Dissertation, Graduate Studies in Civil Engineer Program, Federal University of Santa Catarina, Florianópolis, Brazil, 2013

[25] E. S. Blissari, L. P. Spricigo, V. Conte, E. Uggioni, and A. M. Bernardin, "Geopolímeros obtidos a partir de cinzas de carvão mineral," Annals of the First Seminar of Research, Extension and Innovation from IF-SC Criciúma campus, Santa Catarina, Criciúma, Brazil, Nov. 2011.

[26] E. N. M. G. Pinto, "Adição de resíduo cerâmico em pastas geopoliméricas para cimentação de poços de petróleo," D. Thesis, Graduate in Science and Materials Engineering, Federal University of Rio Grande do Norte, Natal, 2011.

[27] L. G. A. Melo, "Síntese e caracterização de geopolímeros contendo filitos," MSc. Dissertation, Course of Mechanical and Materials Engineering, Military Institute of Engineer, Rio de Janeiro, Brazil, 2011.

[28] C. S. Bitencourt, B. H. Teider, J. B. Gallo, and V. C. Pandolfelli, “A geopolimerização como técnica para a aplicação do resíduo de bauxita," Cerâmica, vol. 58, pp. 20-28, 2012.

[29] J. Mauri, D. P. Dias, G. C. Cordeiro, and A. A. Dias, "Argamassa geopolimérica: estudo da degradação por sulfato de sódio e ácido sulfúrico," Matéria, vol. 14, pp. 1039-1046, Oct. 2009.

[30] D. S. T. Pereira, F. A. Oliveira, F. J. Silva, and C. Thaumaturgo, "Análise microestrutural de concreto geopolimérico: uma visão comparativa," presented at Inter American Conference on Non-Conventional Materials and Technologies in Ecological and Sustainable Construction, Military Institute of Engineer, Rio de Janeiro, Brazil, Nov. 2005.

[31] C. G. S. Severo, B. S Lira, D. L. Costa, R. R. Menezes, and G. A. Neves, "Ativação alcalina de resíduos minerais com $\mathrm{NaOH}$," Revista Eletrônica de Materiais e Processos, vol. 8, pp. 106-109, July 2013. Available: www.dema.ufcg.edu.br.

[32] M. D. B. Barroso, "Desenvolvimento de compósitos com matriz de geopolímeros reforçados com partículas de quasicristais AlCuFe," D.
Thesis, Graduate in Mechanical Engineering, Federal University of Paraíba, João Pessoa, Brazil, 2009.

[33] S. M. T. D. Sousa, "Efeito da ativação alcalina dos aluminossilicatos nas propriedades mecânicas e microestruturais de compósitos argilosos prensados," D. Thesis, Graduate in Mechanical Engineering, Federal University of Paraíba, João Pessoa, Brazil, 2011.

[34] R. A. A. B. Santa, A. M. Bernardin, H. G. Riella, and N. C. Kuhnen, "Geopolymer synthetized from bottom coal ash and calcined paper sludge," Journal of Cleaner Production, vol. 57, pp. 302-307, May 2013.

[35] S. de Barros et al., "Adhesion of geopolymer bonded joints considering surface treatments," Journal of Adhesion, vol. 88, pp. 364-375, Apr 2012.

[36] J. D. R. B. de Souza, "Adesivos alcalinamente ativados: ativação com silicato de potássio e silicato de sódio," MSc. Dissertation, Graduate in Mechanical Engineering, Federal University of Paraíba, João Pessoa, Brazil, 2009.

[37] F. Pelisser, E. L. Guerrino, M. Menger, M. D. Michel, and J.A. Labrincha, "Micromechanical characterization of metakaolin-based geopolymers," Construction and Building Materials, vol. 49, pp. 547-553, Sept. 2013

[38] M. S. Cilla, P. Colombo, and M. R. Morelli, "Geopolymer foams by gelcasting," Ceramics International, vol. 40, pp. 5723-5730, 2014.

[39] J. D. Altidis, S. D. Barros, J. D. R. B. D. Souza, S. M. Torres, and S. J. G. D. Lima, "Adhesion tests in quasicrystal powders reinforced geopolymer composites," Materials Science Forum, vol. 727-728, pp. 186-189, Aug. 2012.

[40] A. N. Silva et al., "Effect of addition of quasicrystals in the formation of geopolymer matrix composites," Materials Science Forum, vol. 727-728, pp. 1479-1484, Aug. 2012.

[41] Intersindical Department of Statistics and Socioeconomic Studies (DIEESE), "Estudo Setorial da Construção (Study on Construction Sector)," Estudos e Pesquisas, n. 65. São Paulo, Brazil, May 2013.

[42] Brazilian Institute of Geography and Statistics (IBGE), "Pesquisa anual da indústria da construção (Annual survey of construction industry)," Brazil, June 2013.

[43] Brazilian Institute of Geography and Statistics (IBGE), "Sistema de contas nacionais Brasil 2004-2008 (System of national accounts Brazil 2004-2008)," Contas Nacionais, ${ }^{\circ} 31$. Rio de Janeiro, Brazil, 2010.

[44] Institute of Applied Economic Research (IPEA), "Estimativas do déficit habitacional brasileiro (2007-2011) por municípios (2010) (Estimates of the Brazilian housing deficit (2007-2011) by municipalities (2010))," Nota Técnica, n. 1. Brasília, Brazil, May 2013.

[45] Brazil, Law N. 12.305, of August 2, 2010. Institutes the National Policy on Solid Waste, amending Law N. 9,605, of February 12, 1998, and other provisions. Brasília, Distrito Federal, 2010.

[46] Brazil, Law N. 12.187, of December 29, 2009. Institutes the National Policy on Climate Change and other provisions. Brasília, Distrito Federal, 2009

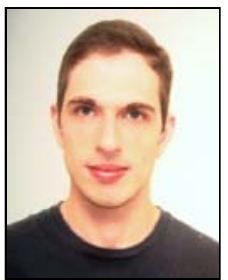

Rodrigo Henrique Geraldo was born in Amparo city, Brazil. He graduated in environmental engineering from College Jaguariúna in 2011, Jaguariúna, Brazil.

$\mathrm{He}$ is working with geopolymers technologies as a MSc Student from Civil Engineering, Architecture and Urban Design College at University of Campinas, UNICAMP.

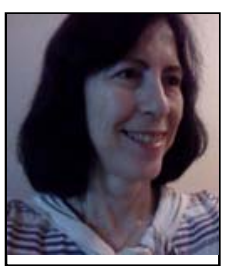

Gladis Camarini is a civil engineer and a professor at School of Civil Engineering, Architecture and Urban Design, University of Campinas. She had her master degree in 1988 and $\mathrm{PhD}$. degree in 1995 at University of São Paulo. She did postdoctoral studies at the Laboratoire des Materiaux et Durabilité des Constructions (LMDC) at Institut National des Sciences Apliquées (INSA, Toulouse, France, 1998). She also did postdoctoral studies at the National Institute for Space Research (INPE, São José dos Campos, Brazil, 2008). Then she also did postdoctoral studies at the Institute of Science and Technology del Hormigón (ICITECH), the Polytechnic School of Valencia (UPV) (Valencia, Spain, 2012). She is a peer reviewer of scientific journals indexed on the Journal Citation Reports, national and international journals, Congress and Seminars, and Brazilian Research Foundations. She is an IACSIT senior member. Her research interests include: building materials, mineral binders, mortars, industrial and construction wastes, reusing and recycling of materials, mortar, concrete, and other composites. 